\title{
Aclimatação morfológica de forrageiras temperadas a padrões e níveis de sombreamento ${ }^{1}$
}

\author{
Américo Fróes Garcez Neto ${ }^{2 *}$, Rasmo Garcia ${ }^{2}$, Derrick Jan Moot $^{3}$, Kátia Fernanda Gobbi ${ }^{2}$ \\ 1 Pesquisa financiada com apoio da Coordenadoria de Aperfeiçoamento de Pessoal de Nível Superior (CAPES). \\ 2 Departamento de Zootecnia, Universidade Federal de Viçosa, Av. P.H. Rolfs, s/n, Campus, CEP: 36570-000, Viçosa, Minas Gerais, Brasil. \\ ${ }^{3}$ Agriculture and Life Science Division, Lincoln University, PO Box 84, Canterbury, New Zealand.
}

RESUMO - As características morfológicas do azevém-perene (Lolium perenne cv. Nui), dátilo (Dactylis glomerata cv. Vision) e trevo-vermelho (Trifolium pratense cv. Pawera) foram avaliadas em resposta a quatro níveis (0, 25, 50 e 75\%) e dois padrões de sombreamento (contínuo e alternado), sob três períodos de crescimento (estabelecimento, primeira e segunda rebrotação), na Nova Zelândia, com o objetivo de avaliar as formas de adaptação de diferentes espécies às mudanças no ambiente luminoso. O estudo foi conduzido em delineamento experimental de blocos completos casualizados, com três repetições, entre janeiro e outubro de 2004. A maioria das medidas morfológicas foi afetada pelos níveis de sombreamento. A área foliar específica foi a variável morfológica que variou mais consistentemente em resposta aos níveis de sombreamento, com aumento de 22 a $79 \%$ entre as forrageiras. As adaptações morfológicas do dátilo foram as que mais se relacionaram à tolerância ao sombreamento, enquanto as do azevém-perene foram mais relacionadas à expansão da sua área foliar individual. A faixa de sombreamento entre 25 e 50\% pode ser considerada a de maior aclimatação morfológica das forrageiras para compensar a restrição luminosa.

Palavras-chave: gramínea, irradiância, leguminosa, morfologia foliar

\section{Morphological acclimation of temperate forages to patterns and levels of shade}

\begin{abstract}
The morphological characteristics of perennial ryegrass (Lolium perenne cv. Nui), cocksfoot (Dactylis glomerata cv. Vision) and red clover (Trifolium pratense cv. Pawera) in response to four shade levels (0, 25, 50 and $75 \%$ ) and two shade patterns (continuous and alternate) were assessed in three growth periods (establishment, first regrowth and second regrowth), in New Zealand, to evaluate the adaptation of different species to changes in the light environment. The experiment was conducted in a randomized complete block design, with three replications, between January and October, 2004. Most of the morphological measurements were affected by the shade levels. The specific leaf area was the morphological variable that most consistently varied in response to shade levels, presenting an average increase between 22 and $79 \%$ among the forage species. The morphological adaptations of cocksfoot were the most related to shade tolerance, whereas for perennial ryegrass they were more related to the expansion of its individual leaf area. The $25-50 \%$ shade range can be considered the range of highest morphological acclimation of forages to offset light constraint.
\end{abstract}

Key Words: irradiance, grass, leaf morphology, legume

\section{Introdução}

Apesar de os sistemas silvipastoris representarem uma alternativa agroflorestal promissora (Sharrow, 1999), variações microclimáticas nesses sistemas ainda têm dificultado a definição de práticas de manejo mais adequadas às forrageiras do sub-bosque. Isso ocorre porque estes sistemas normalmente desenvolvem condições microclimáticas muito mais heterogêneas e dinâmicas que as verificadas nos sistemas tradicionais de produção animal, variando consideravelmente com o tempo (Meloni, 1999) e com o tipo de cobertura arbórea (Bergez et al., 1997; Teklehaimanot et al., 2002).

Entre as variações microclimáticas, as modificações no ambiente luminoso têm merecido grande destaque por influenciarem significativamente a produtividade do pasto (Lin et al., 2001; Belesky, 2005ab). Normalmente, o sombreamento causado pelas árvores leva à redução na radiação incidente e na relação do espectro da luz (ex. vermelho:vermelho-extremo) (Feldhake, 2001), causando 
mudanças significativas na morfologia de muitas forrageiras (Lin et al., 1999).

Essas mudanças nas características morfológicas, por estarem relacionadas à quantidade e qualidade da forragem produzida (Kephart et al., 1992; Kephart et al, 1993), podem ser relevantes na avaliação do efeito do sombreamento sobre o potencial de utilização de forrageiras em sistemas silvipastoris. Entre as modificações morfológicas que interferem na quantidade e qualidade da forragem, pode-se destacar a área, o comprimento, a espessura e orientação da lâmina foliar, o comprimento do colmo, o número de folhas e a relação lâmina:colmo.

Em geral, essas mudanças na morfologia têm sido relacionadas às alterações na digestibilidade da matéria seca, na concentração de nutrientes (Lin et al., 2001) e na interceptação de luz pelo dossel das culturas forrageiras. A estrutura dessas plantas representa uma série de adaptações morfológicas pelas quais as forrageiras passam para melhor se ajustarem ao seu meio de cultivo (Da Silva \& Nascimento Jr., 2007). O conhecimento das diferenças estruturais entre plantas tem sido frequentemente utilizado no planejamento do manejo das forrageiras, de modo que a produção animal nos sistemas de pastejo possa ser melhor explorada (Hodgson, 1990; Da Silva \& Nascimento Jr., 2007). Um exemplo tem sido a recomendação de alturas de pastejo mais adequadas para obtenção de forragem com melhor relação folha/colmo, acúmulo de folhas verdes e valor nutricional (Hodgson, 1990; Carnevalli et al., 2006). No entanto, para determinar uma estrutura mais específica é preciso identificar como diferenças de natureza morfológica se interagem, particularmente em ambientes com grande variabilidade microclimática, como nos sistemas silvipastoris.

Forrageiras como o azevém-perene, o dátilo e o trevovermelho podem ser incluídas entre as principais forrageiras cultivadas em regiões de clima temperado (Kemp et al., 2000; Barnes et al., 2003). O azevém assume especial destaque em regiões insulares, como na Nova Zelândia e Inglaterra, representado nesses países a principal gramínea forrageira. O dátilo é uma gramínea que tem se destacado em regiões continentais, como a Europa ocidental e os Estados Unidos (Barnes et al., 2003). Nessas regiões, essa forrageira apresenta melhor adaptação ao inverno local, a situações de maior déficit hídrico e menor luminosidade. O trevovermelho é uma leguminosa fixadora de nitrogênio de alto valor nutricional em comparação à maioria das gramíneas forrageiras. No entanto, a análise comparativa dessas espécies em condição de sombreamento a campo não tem sido amplamente avaliada e na maioria das vezes está limitada a condições de cultivo em casa de vegetação.
Considerando a importância da morfologia na produção e utilização das forrageiras em pastos cultivados, foi desenvolvido um experimento com o objetivo de avaliar a influência de diferentes níveis de atenuação luminosa e padrões de distribuição da luz sobre características de adaptação morfológica do azevém-perene, dátilo e trevovermelho com propriedades morfofisiológicas.

\section{Material e Métodos}

O experimento foi realizado entre janeiro e outubro de 2004 na Lincoln University, Canterbury, Nova Zelândia (latitude $43^{\circ} 38^{\prime}$ Sul, longitude $172^{\circ} 30^{\prime}$ Leste). O solo, classificado como Templeton silt loam, consiste de uma camada de 1 a $2 \mathrm{~m}$ de sedimentos aluviais finos sobre cascalho. O clima é descrito como temperado e subúmido e a média anual de precipitação pluvial de $632 \mathrm{~mm}$ (média dos últimos 30 anos), razoavelmente distribuída ao longo do ano, com média anual de evapotranspiração potencial de $1.300 \mathrm{~mm}$. A temperatura média anual é de $11,5{ }^{\circ} \mathrm{C}$ (média dos últimos 30 anos), com temperaturas médias mensais entre maio e setembro abaixo de $10{ }^{\circ} \mathrm{C}$. A área experimental, previamente ao estabelecimento do experimento, foi cultivada com forrageiras, gramíneas e leguminosas herbáceas e submetida aos procedimentos normais de correção e adubação do solo para evitar qualquer problema decorrente de deficiências nutricionais.

O estudo foi conduzido com três espécies forrageiras (duas gramíneas e uma leguminosa) em monocultivo. As gramíneas estudadas foram o dátilo (Dactylis glomerata cv. Vision) e o azevém-perene (Lolium perenne cv. Nui), e a leguminosa, o trevo-vermelho (Trifolium pratense cv. Pawera). As espécies foram semeadas em 1/1/2004, após preparo convencional do solo, com espaçamento de $15 \mathrm{~cm}$ entre linhas, em faixas paralelas e individuais de $2 \times 20 \mathrm{~m}$ no sentido norte-sul, em terreno de topografia plana. As taxas de semeadura foram de 7, 14 e $23 \mathrm{~kg} / \mathrm{ha}$, para o dátilo, azevém-perene e trevo-vermelho, respectivamente.

Os tratamentos envolveram quatro níveis de irradiância e dois padrões de irradiância para cada espécie forrageira, de acordo com o delineamento em blocos completos casualizados, com três repetições. O estudo foi conduzido em três fases distintas: crescimento de estabelecimento (verão-outono); primeira rebrotação (outono-inverno); e segunda rebrotação (inverno-primavera).

Os níveis de irradiância foram obtidos por meio de estruturas de sombreamento artificial, dispostas no campo perpendicularmente sobre as faixas das forrageiras logo após a semeadura. As estruturas, de formato retangular, foram compostas por uma cobertura de tábuas de madeira 
montadas transversalmente sobre um suporte de tubos de metal, de modo que a cobertura fosse mantida a $50 \mathrm{~cm}$ do nível do solo e a estrutura cobrisse todas as parcelas. Os níveis de irradiância foram estabelecidos pela combinação da distância entre faixas de tábuas e espaços vazios sobre as estruturas.

A área de cada unidade experimental (parcela), resultante da combinação das estruturas de sombreamento com as faixas das forrageiras, foi de 2,0 × 2,4 m. Os níveis de sombreamento artificial foram: 0 (sem sombreamento artificial), 25, 50 e 75\%, correspondendo, respectivamente, a 100, 75, 50 e 25\% de transmissão de luz, expressa em termos de radiação fotossinteticamente ativa incidente.

Adicionalmente às estruturas com cobertura de madeira, foram utilizadas estruturas com cobertura de sombrite com 50\% de transmissão luminosa para obtenção do padrão de sombreamento contínuo, utilizadas para comparação dos padrões de luminosidade das estruturas com cobertura de madeira (sombreamento alternado) com o mesmo nível de transmissão luminosa.

Os níveis e padrões de irradiância foram monitorados com o uso de sensores quânticos (Licor LI-190SA; Li-Cor Biosciences, Inc., Lincoln, USA) instalados acima e abaixo das coberturas, mas acima do dossel das plantas. Esses sensores foram conectados a uma estação microclimática localizada no campo experimental, a qual registrava a radiação a cada cinco minutos por meio de uma unidade de memória (CR21X, Campbell Scientific Ltda., UK).

Cada fase de avaliação representou um ciclo de crescimento, que foi concluído com o corte das plantas. Durante os três ciclos de crescimento, as plantas de todos os tratamentos foram monitoradas quanto à interceptação de luz pelo dossel a intervalos semanais. Quando a interceptação luminosa de um dos tratamentos atingia entre 99 e $100 \%$, medidas de morfologia do dossel eram feitas em todos os tratamentos. Após esse procedimento, as plantas de todas as parcelas foram submetidas a um corte de uniformização a uma altura de 25 mm do solo.

Para o cálculo da interceptação de luz de cada parcela, foi utilizado o ceptômetro (Sunfleck Ceptometer, Decagon Devices, USA), com o qual foram feitas leituras da radiação fotossinteticamente ativa (RFA), tanto acima (uma leitura) quanto abaixo do dossel (cinco leituras). O percentual de interceptação luminosa foi calculado como a quantidade da RFA interceptada (RFA acima do dossel menos RFA abaixo do dossel) dividida pela RFA acima do dossel, e multiplicando o resultado por 100. As leituras foram realizadas sem as coberturas de sombreamento em dias não-nublados, uma vez que os sensores quânticos que compõem o aparelho são mais indicados para uso sob luz direta.

Antes do corte de uniformização em cada período de avaliação, o comprimento das lâminas foliares de quatro perfilhos representativos da altura média do dossel foi medido com o uso de régua graduada, assim como o comprimento do pseudocolmo (tido como a distância entre o nível do solo e a lígula da folha mais nova completamente expandida). Também foram contados nesses perfilhos o número total de folhas e o número de folhas verdes por perfilho. Na leguminosa, foi medido o comprimento do pecíolo. Logo após essas medidas de morfologia, e anteriormente ao corte de uniformização, foram colhidas amostras de forragem de quadros de amostragem de $0,20 \mathrm{~m}^{2}$. Foi colhida uma amostra por parcela a $25 \mathrm{~mm}$ de altura do nível do solo. O material colhido foi colocado em sacos plásticos, dentro de caixa térmica com gelo, até que fosse levado à câmara fria do laboratório para posterior processamento. Todas as amostras colhidas foram armazenadas em câmara fria por aproximadamente 24 horas, enquanto as parcelas eram uniformizadas com o uso de uma roçadeira.

Finalizada a uniformização, uma subamostra de dez perfilhos proveniente dos quadros foi separada para determinação da área foliar específica. As folhas (lâminas foliares) dos perfilhos foram separadas em folha mais nova completamente expandida e demais folhas do perfilho. Essas folhas foram distribuídas sobre um fundo branco e cobertas por uma placa de vidro transparente para que fossem tiradas fotografias com o uso de uma máquina fotográfica digital. Depois de feitas as fotografias, as folhas foram colocadas em sacos de papel e levadas a estufa de ventilação forçada a $65^{\circ} \mathrm{C}$ por 72 horas. Os arquivos das fotos digitais foram posteriormente analisados em um software para análise de imagens para o cálculo da área foliar total e da última folha recém expandida. De posse do peso total da matéria seca e da área total das folhas, foi possível calcular a área foliar específica das gramíneas. No caso da leguminosa, foi adotado o mesmo procedimento em uma subamostra de 20 folhas (trifólios + pecíolos). No entanto, nessa espécie, a área foliar foi definida como a área média do trifólio. Uma subamostra de 50 g das gramíneas e da leguminosa foi utilizada para o cálculo da relação lâmina:colmo, a partir da separação botânica das lâminas foliares, pseudocolmo e pecíolo.

Os dados foram analisados utilizando-se os procedimentos GLM (General Linear Models) e REG (Regression) disponíveis no pacote estatístico Statistical Analysis System (SAS, 1990). As espécies forrageiras 
foram avaliadas de forma independente entre os períodos de crescimento. As regressões entre as variáveis medidas e os níveis de atenuação luminosa foram determinadas utilizando-se 10 (quadrática) e 11 (linear) graus de liberdade para o erro. O coeficiente de determinação ajustado, a significância da regressão, testada pelo teste $F$, e a significância dos coeficientes de regressão, testados pelo teste t, foram utilizados na avaliação do grau de ajustamento das funções. As comparações entre os padrões de luminosidade foram realizadas utilizando-se o teste $\mathrm{F}$.

\section{Resultados e Discussão}

Apesar de a precipitação pluvial acumulada $(645 \mathrm{~mm})$ e a temperatura média do ar $\left(11,1^{\circ} \mathrm{C}\right)$ do ano de 2004 terem ficado muito próximas das médias históricas, a precipitação acumulada até o final do experimento registrou um déficit de $63 \mathrm{~mm}$ (469 vs $532 \mathrm{~mm}$ ) (Figura 1).

A maioria das características morfológicas avaliadas respondeu significativamente ao sombreamento. Apenas a área foliar da folha mais nova completamente expandida e a relação lâmina:colmo do dátilo não apresentaram resposta significativa $(\mathrm{P}>0,05)$ aos níveis de sombreamento. De modo contrário, apenas o comprimento do pseudocolmo do azevém-perene e o pecíolo do trevo-vermelho responderam $(\mathrm{P}<0,05)$ ao padrão de sombreamento. Enquanto o comprimento do pseudocolmo do azevém-perene foi maior (77vs $71 \mathrm{~mm}$ ) com o sombreamento contínuo, o comprimento do pecíolo do trevo-vermelho foi maior (94 vs $80 \mathrm{~mm}$ ) com o sombreamento alternado. A análise comparativa entre forrageiras sob sombreamento contínuo e alternado, até então, não tem sido abordada em experimentos dessa natureza.

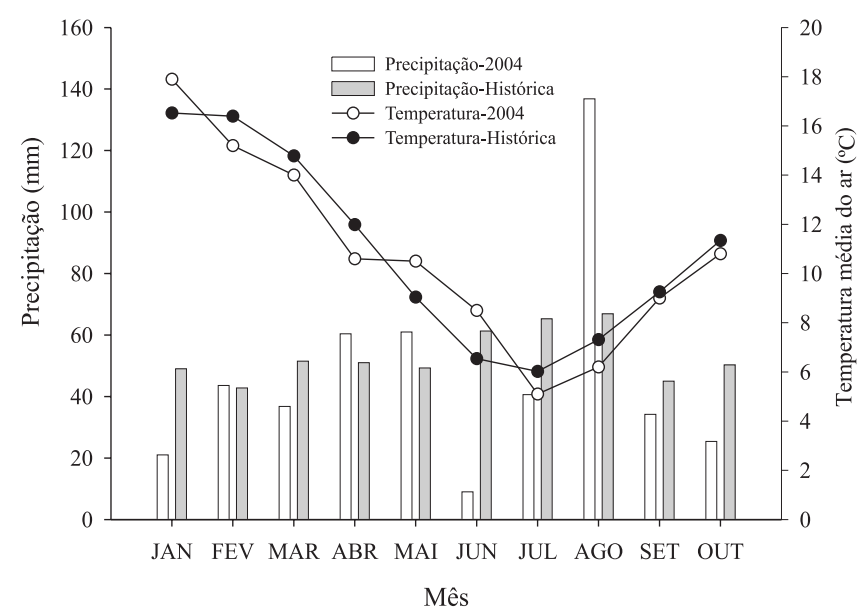

Figura 1 - Temperaturas médias mensais e precipitação pluvial de janeiro a outubro de 2004, e médias históricas dos últimos 30 anos (1973-2003).
A área foliar do azevém-perene foi maior entre 25 e 50\% de sombreamento durante o crescimento de estabelecimento e a primeira rebrotação. Na segunda rebrotação, a área foliar aumentou linearmente com os níveis de sombreamento. No trevo-vermelho, também foi observada maior área foliar entre 25 e $50 \%$ de sombreamento. No entanto, essa maior área foliar entre esses níveis de sombreamento ocorreu apenas para a primeira e a segunda rebrotação. Durante o crescimento de estabelecimento, a área foliar do trevovermelho reduziu linearmente com os níveis de sombreamento (Figura 2). Espécies que apresentam crescimento inicial lento, como é o caso do trevo-vermelho, precisam, relativamente, de maiores níveis de radiação incidente para manter a mesma taxa de acúmulo que espécies de crescimento inicial mais acelerado (Sinclair \& Horie, 1989).

No azevém-perene e trevo-vermelho, a plasticidade morfológica em termos de área foliar apresentou comportamento diferente em resposta aos níveis de sombreamento e às fases de avaliação. Na primeira rebrotação, não houve diferenças no padrão das respostas encontradas na área foliar em ambas as espécies. A área foliar aumentou em torno do sombreamento de $25 \%$. No entanto, no estabelecimento esse padrão foi observado apenas no azevém-perene, enquanto no trevo-vermelho isso ocorreu na segunda rebrotação. Isso sugere que a margem de aumento da área foliar não é muito expressiva acima de $25 \%$ de sombreamento (Figura 2), o que de alguma forma pode comprometer a captura de luz pelo dossel e a produção de forragem. O aumento da área foliar tem sido uma das principais adaptações morfológicas das plantas para compensar reduções na radiação incidente. No entanto, essa expansão precisa estar ajustada ao acúmulo suficiente de reservas e à manutenção da população de plantas na área (Peri et al., 2007). Abaixo de determinados níveis de radiação incidente, o acúmulo de carboidratos fica prejudicado pela baixa capacidade fotossintética, o que limita a expansão foliar (Peri et al., 2003).

Uma diferença entre o azevém-perene e o trevo-vermelho, em relação à expansão da área foliar, é o tipo de manejo em condição de sombreamento. No estabelecimento, o trevovermelho é mais lento que o azevém-perene (Kemp et al., 2000; Lucas et al., 2003), o que torna essa espécie mais dependente da disponibilidade de luz para maior produção de assimilados, particularmente aqueles utilizados na expansão da área foliar. Acredita-se que o trevo-vermelho, neste trabalho, pode não ter acumulado assimilados suficientes para expandir a área foliar de modo a aumentar a capacidade de interceptação de luz sob sombreamento, o que pode explicar a queda consistente na relação lâmina:colmo do trevovermelho, sobretudo na fase de estabelecimento (Figura 2). 

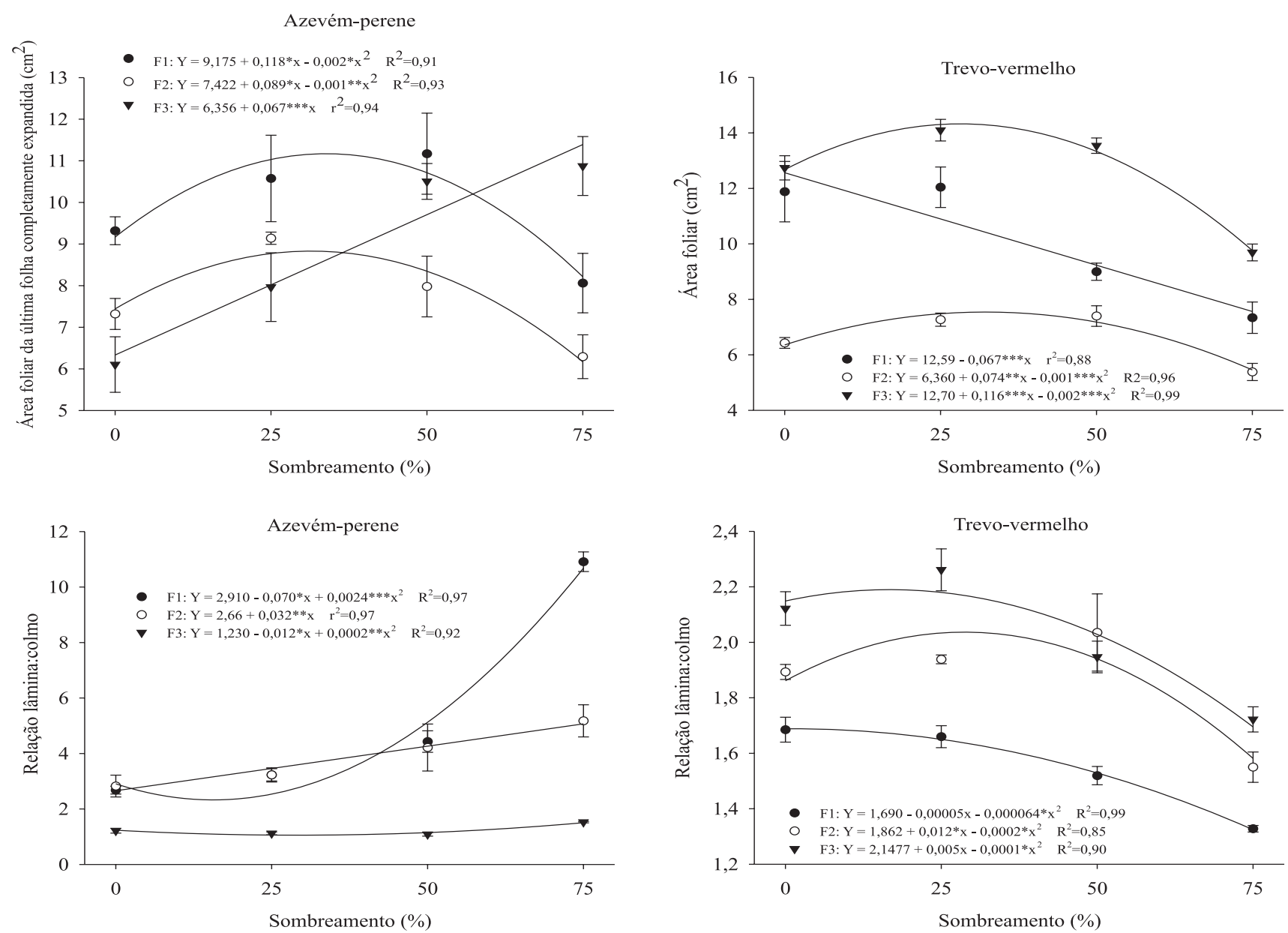

F1: crescimento de estabelecimento; F2: primeira rebrotação; F3: segunda rebrotação. Significativo: *** 0,1\%; ** 1\%; *5\%. Barras: erro-padrão da média (n = 3).

Figura 2 - Área foliar e relação lâmina:colmo do azevém-perene e trevo-vermelho nos períodos de avaliação em resposta aos níveis de sombreamento.

O aumento linear na área foliar do azevém-perene com o sombreamento, na segunda rebrotação, pode estar relacionado a uma provável deficiência de nitrogênio com a redução do sombreamento, que não pôde ser compensada pelos maiores níveis de irradiância. Como o azevém-perene é uma gramínea com alta capacidade de extração de nitrogênio (Whitehead, 2000) e, no estabelecimento, a produção foi maior com a redução do sombreamento, na segunda rebrotação, pode ter havido interação entre o nível de irradiância e a disponibilidade de nitrogênio no solo, de modo que, mesmo sob sombreamento intenso, ainda houve expressivo aumento da área foliar pela maior disponibilidade de nitrogênio. Uma análise das folhas nessa fase confirmou o aumento na concentração de nitrogênio com o sombreamento. Contrariamente ao trevovermelho, a relação lâmina:colmo do azevém-perene aumentou com o sombreamento. Esse fato revela a boa capacidade de expansão da área foliar do azevém-perene em combinação com o pouco alongamento do pseudocolmo, principalmente nas fases de estabelecimento e primeira rebrotação (Figuras 3 e 2).

Apesar de o comprimento das lâminas foliares das gramíneas ter aumentado com o sombreamento (Figura 4), essa mudança, em termos de dimensão linear, não alterou significativamente a área foliar do dátilo. Peri et al. (2004) verificaram que, em folhas de dátilo submetidas a intenso sombreamento, apesar de aumentarem em 33\% o comprimento da lâmina, a largura reduziu até $22 \%$. Essa compensação verificada em termos de dimensões lineares pode ter sido a causa para a ausência de variações significativas na área foliar do dátilo neste trabalho.

O comprimento do pseudocolmo e pecíolo foram afetados pelos níveis de sombreamento (Figura 3). No crescimento de estabelecimento, apesar da pequena variação, apenas o comprimento do pseudocolmo do azevém-perene respondeu significativamente aos níveis de sombreamento. Enquanto na primeira rebrotação o dátilo aumentou linearmente o comprimento do pseudocolmo 
com os níveis de sombreamento, na segunda rebrotação, o comprimento do pecíolo do trevo-vermelho foi reduzido de forma linear (Figura 3). Em geral, o aumento no comprimento do pseudocolmo ou pecíolo como forma de aumentar a captura de luz é limitado acima de $50 \%$ de sombreamento (Lin et al., 2001).
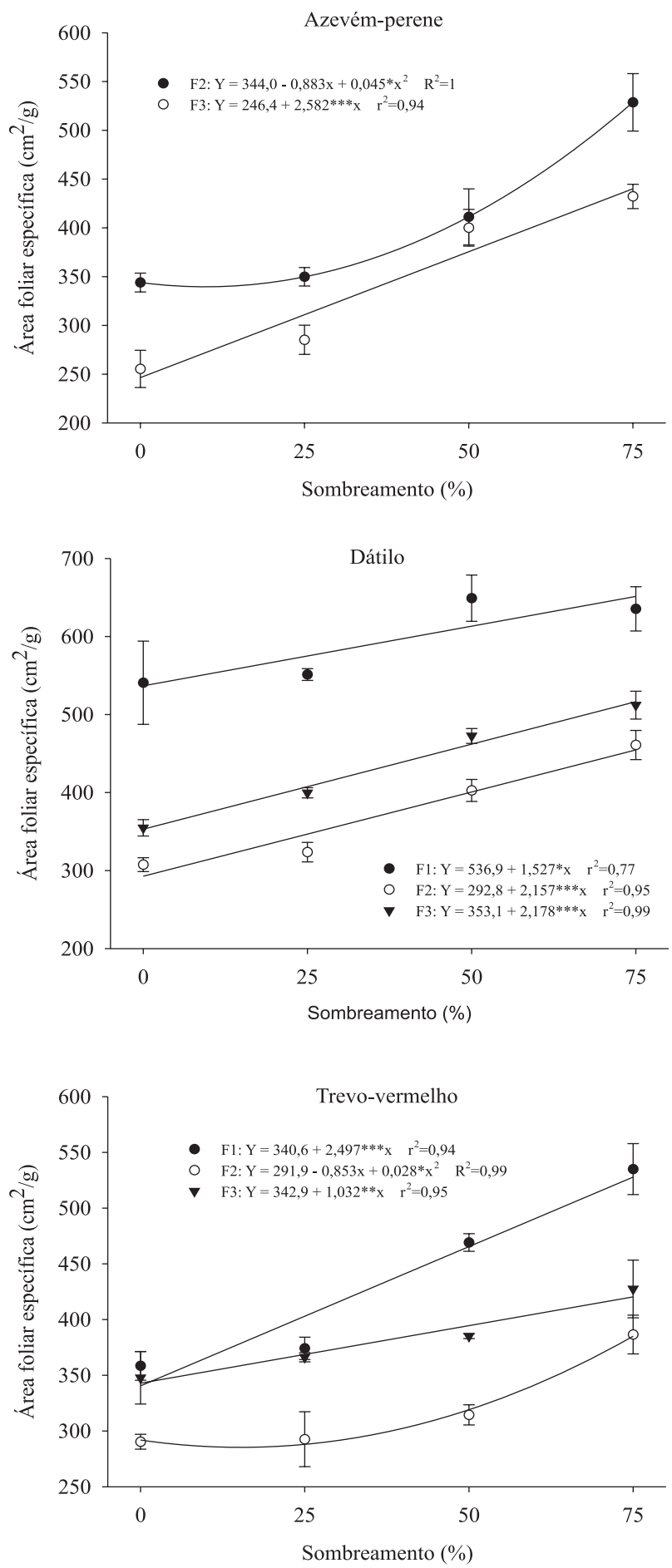

A área foliar específica das forrageiras aumentou significativamente $(\mathrm{P}<0,05)$ com os níveis de sombreamento (Figura 3). O aumento variou de 54 a 79\% no azevém-perene e de 22 a 55\% no dátilo e trevo-vermelho. No entanto, esses aumentos não ocorreram da mesma forma entre as espécies e períodos de avaliação. Enquanto no trevo-vermelho o
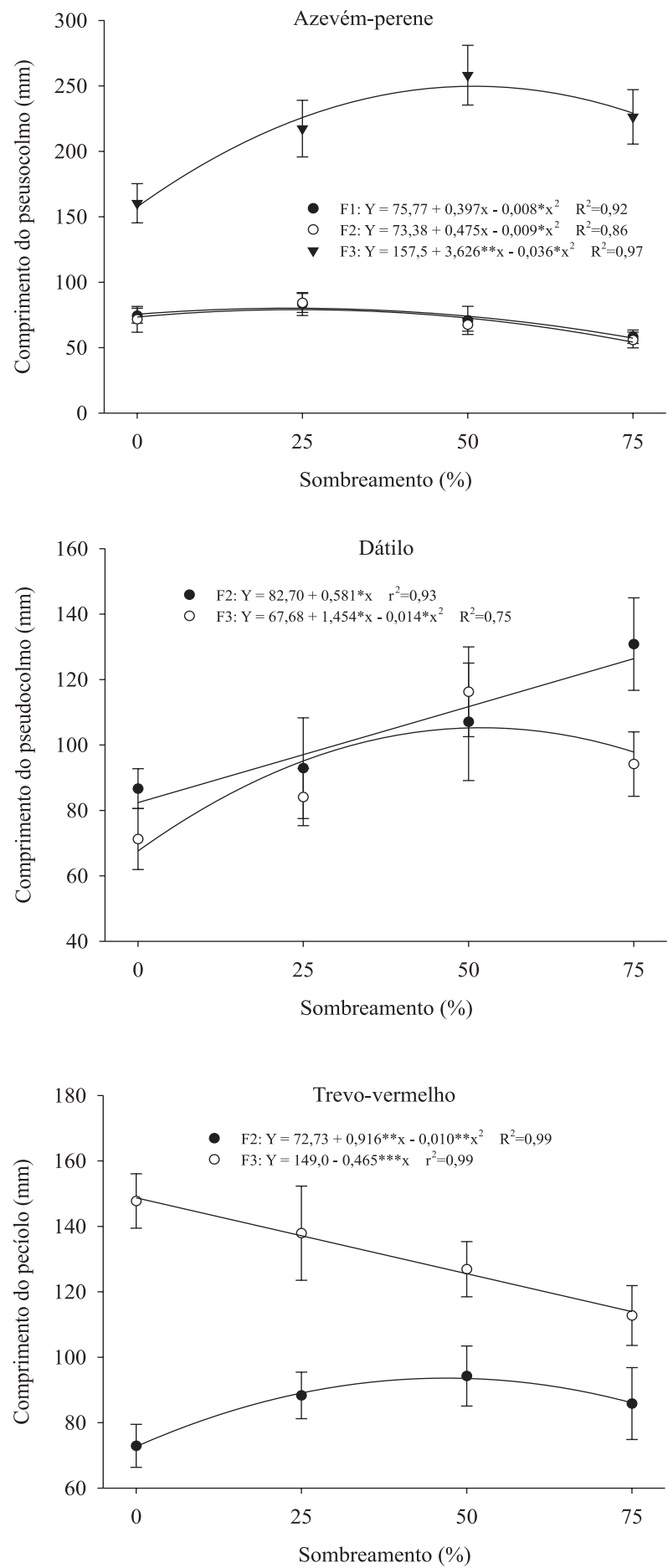

F1: crescimento de estabelecimento; F2: primeira rebrotação; F3: segunda rebrotação. Significativo: *** 0,1\%; ** 1\%; *5\%. Barras: erro padrão da média (n = 3).

Figura 3 - Área foliar específica e comprimento do pseudocolmo e pecíolo do azevém-perene, dátilo e trevo-vermelho nos períodos de avaliação em resposta aos níveis de sombreamento. 
maior aumento ocorreu na primeira fase, no dátilo isso ocorreu na segunda fase e, no azevém-perene, na terceira (Figura 3).

O aumento na área foliar específica das plantas com o sombreamento representou o padrão esperado de resposta dessa variável (Poorter \& Evans, 1998, Lambers et al., 1998; Belesky, 2005b). Em geral, esse padrão indica que as lâminas foliares podem ter ficado menos espessas e/ou densas. Essas mudanças morfológicas podem resultar em modificações estruturais no dossel, alterando a capacidade de interceptação de luz e, provavelmente, a produção de forragem. Isso ocorre pela diminuição da resistência mecânica da lâmina foliar com o aumento simultâneo do comprimento da lâmina e da área foliar específica com o sombreamento (Peri et al., 2004), conforme constatado para o azevém (Figuras 3 e 4).

No azevém-perene, o aumento na área foliar com o sombreamento e a ausência de mudanças significativas na área foliar específica podem ter mantido maior ângulo foliar médio do dossel no estabelecimento. No entanto, na rebrotação o aumento na área foliar esteve associado ao aumento significativo da área foliar específica, o que pode ter causado diminuição do ângulo foliar médio do dossel. Esse fato está de acordo com o encontrado por Peri et al. (2004) para o dátilo e comprova os ajustes morfológicos que podem ocorrer com o sombreamento. Esses autores verificaram que o aumento simultâneo da área foliar específica e do comprimento da lâmina com o sombreamento reduziu o ângulo foliar médio do dossel de $68^{\circ}$ para $59^{\circ}$. Embora esse padrão não tenha sido observado no dátilo neste trabalho,

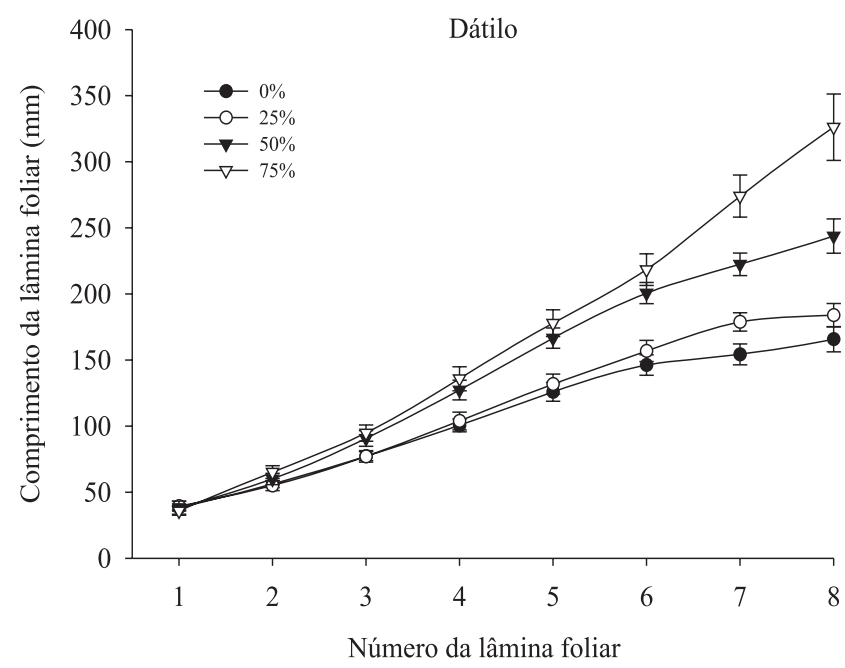

Barras: erro-padrão da média $(\mathrm{n}=3)$. a diminuição do ângulo foliar médio com o sombreamento pode indicar adaptação morfológica para maior captura de luz, pois as folhas podem se distribuir sobre maior área no plano horizontal. A relação negativa entre área foliar específica e produção de forragem observada por Kephart et al. (1992) e Belesky (2005ab) confirmam a importância que os ajustes morfológicos podem ter na determinação do potencial de produção das forrageiras sob sombreamento, particularmente quando esses ajustes estão relacionados à interceptação luminosa pelo dossel.

Embora tenha sido encontrada reposta significativa do número de folhas verdes ao nível de sombreamento, os resultados não permitem conclusões mais abrangentes, uma vez que esses efeitos foram muito isolados em termos de espécie e fase de avaliação. No entanto, o padrão encontrado esteve de acordo com resultados de outros autores que apontam para menor senescência e maior proporção de tecidos verdes quando o sombreamento abrange todo perfil do dossel (Sharrow, 1999; Hikosaka, 2005). Neste trabalho, enquanto a redução na proporção de material morto no estabelecimento não foi significativa, na primeira e segunda rebrotação essa redução foi de 33 a 90\%. Esse mesmo padrão na alocação de carbono entre crescimento de estabelecimento e rebrotação com o sombreamento também foi confirmado por Cruz (1997) em estudo com gramínea tropical.

Em relação ao número total de folhas, os resultados parecem menos consistentes que no número de folhas verdes. A análise dos dados revelou que a variação mais consistente no número total de folhas esteve mais relacionada

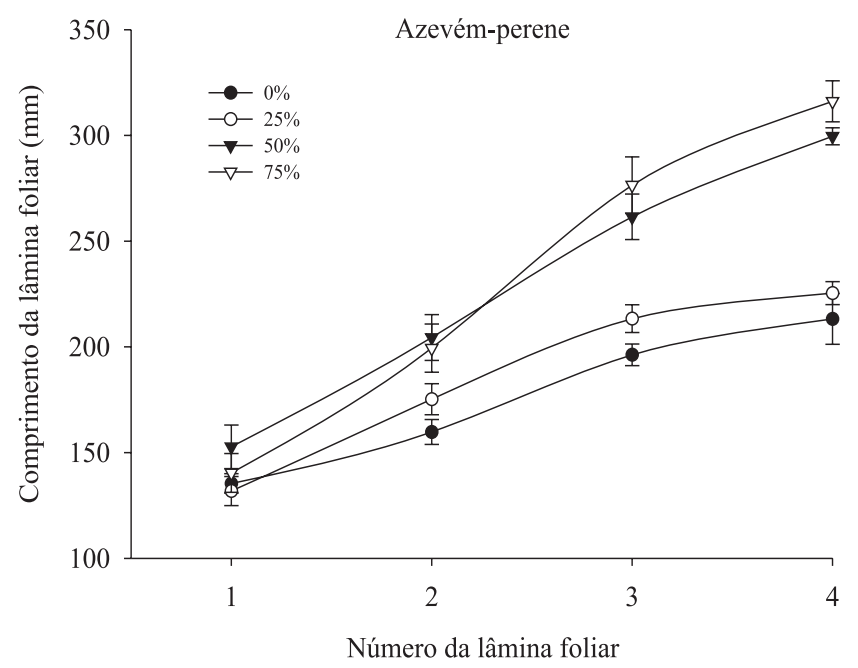

Figura 4 - Comprimento das lâminas foliares do dátilo na fase de estabelecimento e do azevém-perene na segunda rebrotação em resposta aos níveis de sombreamento. 
aos períodos de avaliação que aos níveis de sombreamento. Duru \& Ducrocq (2000) verificaram que, apesar de a radiação ser um aspecto que pode interferir na dinâmica de folhas no dossel, o aumento da temperatura constitui fator determinante no aumento da taxa de aparecimento de folhas do dátilo. Talvez essa seja uma razão para o maior número de folhas encontrado no período de estabelecimento e na segunda rebrotação, quando as temperaturas eram mais elevadas, que na primeira rebrotação (Figura 1).

Algumas características estruturais têm sido utilizadas eficientemente para orientar decisões de manejo em pastos convencionais (sob pleno sol), entre elas, a altura do dossel, como resultado de uma série de adaptações morfológicas, tem representado um importante referencial para técnicos e produtores, mostrando-se consistente entre diferentes situações de manejo. No entanto, o ambiente silvipastoril (sombreamento) proporciona condição microambiental normalmente muito mais dinâmica que a encontrada em pastos a pleno sol. Essas variações microclimáticas, ao alterarem significativamente a direção das mudanças morfológicas, acabam determinando uma condição estrutural própria de um ambiente completamente diferente da situação a pleno sol. Nessas condições, a estrutura da forrageira tomada como referência para o manejo deve ser analisada em conjunto com a capacidade de adaptação morfológica das espécies ao ambiente sombreado.

\section{Conclusões}

O sombreamento contínuo ou alternado não representa o principal fator para a aclimatação morfológica do azevém, do dátilo e do trevo-vermelho quando submetidos a 50\% de sombreamento. As adaptações morfológicas do dátilo foram as que melhor se relacionaram à tolerância dessa espécie ao sombreamento. A faixa de sombreamento entre 25 e $50 \%$ pode ser considerada de maior aclimatação morfológica das forrageiras estudadas para compensar a restrição luminosa.

\section{Agradecimentos}

Ao Dr. Keith Pollock, da Lincoln Univeristy - Nova Zelândia, pelo excelente apoio técnico na condução deste trabalho de pesquisa.

\section{Referências}

BARNES, R.F.; NELSON, C.J.; COLLINS, M. et al. Forages: An introduction to grassland agriculture. 6.ed. Ames: WileyBlackwell, 2003. v.1. 556p.
BELESKY, D.P. Growth of Dactylis glomerata along a light gradient in the central Appalachian region of the eastern USA: I. Dry matter production and partitioning. Agroforestry Systems, v.65, p.81-90, 2005a.

BELESKY, D.P. Growth of Dactylis glomerata along a light gradient in the central Appalachian region of the eastern USA: II. Mechanisms of leaf dry matter production. Agroforestry Systems, v.65, p.91-98, 2005b.

BERGEZ, J.E.; DALZIEL, A.J.I.; DULLER, C. et al. Light modification in a developing silvopastoral system in the UK: a quantitative analysis. Agroforestry Systems, v.37, p.227-240, 1997.

CARNEVALLI, R.A.; DA SILVA, S.C.; BUENO, A.A.O. et al. Herbage production and grazing losses in Panicum maximum cv. Mombaça under four grazing managements. Tropical Grasslands, v.40, p.165-176, 2006.

CRUZ, P. Effect of shade on the carbon and nitrogen allocation in a perennial tropical grass, Dichanthium aristatum. Journal of Experimental Botany, v.48, p.15-24, 1997.

DA SILVA, S.C.; NASCIMENTO JR., D. Avanços na pesquisa com plantas forrageiras tropicais em pastagens: características morfofisiológicas e manejo do pastejo. Revista Brasileira de Zootecnia, v.36, p.121-138, 2007 (supl. especial).

DURU, M.; DUCROCQ, H. Growth and senescence of the successive grass leaves on a tiller. Ontogenic development and effect of temperature. Annals of Botany, v.85, p.635-643, 2000.

FELDHAKE, C.M. Microclimate of a natural pasture under planted Robinia pseudoacacia in central Appalachia, West Virginia. Agroforestry Systems, v.53, p.297-303, 2001.

HIKOSAKA, K. Leaf canopy as a dynamic system: Ecophysiology and optimality in leaf turnover. Annals of Botany, v.95, p.521-533, 2005.

HODGSON, J. Grazing management: science into practice. New York: John Wiley \& Sons, 1990. 203p.

KEMP, P.D.; MATTHEW, C.; LUCAS, R.J. Pastures species and cultivars. In: WHITE, J.; HODGSON, J. (Eds.) New Zealand pasture and crop science. Auckland: Oxford University Press, 2000. 67-99p.

KEPHART, K.D.; BUXTON, D.R.; TAYLOR, S.E. Growth of $\mathrm{C}_{3}$ and $\mathrm{C}_{4}$ perennial grasses under reduced irradiance. Crop Science, v.32, p.1033-1032, 1992.

KEPHART, K.D.; BUXTON, D.R. Forage quality responses of $\mathrm{C}_{3}$ and $\mathrm{C}_{4}$ perennial grasses to shade. Crop Science, v.33, p.831-837, 1993.

LAMBERS, H.; CHAPIN III, F.S.; PONS, T.L. Plant Physiological Ecology. New York: Springer-Verlag, 1998. 540p.

LIN, C.H.; McGRAW, R.L.; GEORGE, M.F. et al. Shade effects on forage crops with potential in temperate agroforestry practices. Agroforestry Systems, v.44, p.109-119, 1999.

LIN, C.H.; McGRAW, R.L.; GEORGE, M.F. et al. Nutritive quality and morphological development under partial shade of some forage species with agroforestry potential. Agroforestry Systems, v.53, p.269-281, 2001.

LUCAS, R.J.; MOOT, D.J.; CAMERON, M.R. et al. Pastures. In: FLEMING P.H. (Ed.) Farm technical manual - Lincoln University. Christchurch: The Caxton Press, 2003. p.1-75, section 3.

MELONI, S. A simplified description of the three-dimensional structure of agroforestry trees for use with a radiative transfer model. Agroforestry Systems, v.43, p.121-134, 1999.

PERI, P.L.; LUCAS, R.J.; MOOT, D.J. Dry matter production, morphology and nutritive value of Dactylis glomerata growing under different light regimes. Agroforestry Systems, v.70, p.63-79, 2007.

PERI, P.L.; MOOT, D.J.; McNEIL, D.L. An integrated model for predicting maximum net photosynthetic rate of Cocksfoot (Dactylis glomerata) leaves in silvopastoral systems. Agroforestry Systems, v.58, p.173-183, 2003.

PERI, P.L.; MOOT, D.J.; LUCAS, R.J. et al. Morphological and anatomical adaptations of Cocksfoot leaves grown under different fluctuating light regimes in New Zealand. In: WORLD 
CONGRESS OF AGROFORESTRY, 1., 2004, Orlando. Proceedings... Orlando: University of Florida, 2004. p390. POORTER, H.; EVANS, J.R. Photosynthetic nitrogen-use efficiency of species that differ inherently in specific leaf area. Oecologia, v.116, p.26-37, 1998.

SHARROW, S.H. Silvopastoralism: Competition and facilitation between tress, livestock, and improved grass-clover pasture on temperate rainfed lands. In: BUCK, L.E.; LASSOIE, J.P.; FERNANDES, E.C.M. (Eds.) Agroforestry in sustainable agricultural systems. Boca Raton: CRC Press, 1999. p.111-130.
SINCLAIR, T.R.; HORIE, T. Leaf nitrogen, photosynthesis, and crop radiation use efficiency: a review. Crop Science, v.29, p.90-98, 1989.

TEKLEHAIMANOT, Z.; JONES, M.; SINCLAIR, F.L. Tree and livestock productivity in relation to tree planting configuration in a silvopastoral system in North Wales, UK. Agroforestry Systems, v.56, p.47-55, 2002.

WHITEHEAD, D.C. Nutrient elements in grassland: soilplant-animal relationships. Wallingford: CAB International, 2000. 369p. 